\title{
Tooth size and metabolic requirements in Primates: The 'equivalence between exponents' under discussion
}

\author{
Tamaño de la dentición y requerimientos metabólicos en Primates: \\ La 'equivalencia entre exponentes' bajo discusión
}

Juan Manuel Jiménez-Arenas,********

JIMÉNEZ-ARENAS, J. M. Tooth size and metabolic requirements in Primates: The 'equivalence between exponents' under discussion. Int. J. Morphol., 31(4):1191-1197, 2013.

SUMMARY: The functional significance of teeth size, specifically postcanine tooth size has contributed a vast amount of scientific literature. Nevertheless, these studies have been based on 'equivalence between exponents'. That is, when the tooth size scales to the 0.75 power of body size exponent is interpreted as reflecting differences in metabolic requirements. On the contrary, if the obtained exponent is close to isometry, such slope is interpreted as that variation in teeth size is an incidental consequence of body size variation. In this paper, we show the results of a study in which the relationship between postcanine tooth occlusal area (PCOA) and basal metabolic rate (BMR) has been evaluated in 28 primate species. On one hand, the results obtained indicate that there is a high correlation between the BMR and the size of the PCOA, even when phylogenetic control tests are used, and that isometry cannot be discarded in both cases. However, if the effects of body mass are removed, a null slope cannot be discarded. On the other hand, when body mass (BM) is taken as the independent variable and PCOA as the dependent one, the slope obtained evidences a negative allometry, and this holds also when phylogenetic control is used. Given these contradictory results, we suggest that the rule of 'equivalence between exponents' is not a good approach for obtaining inferences on the function of postcanine teeth. The argument for the existence or absence of a given relationship between two variables is based on the $p$ value used for testing the null hypothesis $\mathrm{H}_{0}\left(\beta_{1}=0\right)$, which is independent of the value taken by the slope of one of these variables when regressed on a third one. In any case, BM emerges as a key factor in the relationship between PCOA and BRM.

KEY WORDS: Postcanine tooth size; Basal metabolic rate; Allometry; Body size.

\section{INTRODUCTION}

Postcanine teeth are used in oral processing of food for diminishing particle size before digestion. For this reason, and given that tooth size relates in part with the total amount of food processed, many researchers have suggested that there must be a relationship between tooth size and individual metabolic requirements. For example, Pilbeam \& Gould (1974) indicated that tooth size scales to the 0.75 power of skull length, a measurement used as a proxy of body mass. The value of the exponent (3/4) was the one considered by that times as universal for metabolic relationships (Kleiber, 1961). Therefore, variation in tooth size, especially when concerning the dimensions of postcanine teeth, was conceived by Pilbeam \& Gould as reflecting differences in metabolic requirements among mammals. This interpretation resulted in a myriad of articles aimed to evaluate the relationship between tooth size and body mass in different primate groups (for review, see Copes \& Schwartz, 2010).
In several studies the exponent adjusted was positive, which was interpreted as indicating a relationship of tooth size with metabolic rate. In others, the scaling exponent did not depart from the expectations of isometry (2/3), which provided evidence of an incidental variation of tooth size resulting from changes in body mass. Finally, some studies showed negative exponents.

In the specific case of primates, the results obtained from regressions between body size and teeth size has been ambiguous and/or uneven, due to the wide variety of variables used, the taxonomical groups included and the number of available observations. So the things, several studies provided allometrically negative slopes (Kay, 1975; Vinyard \& Hanna, 2005); others, isometrically slopes, interpreted as that variation in teeth size is an incidental consequence of body size variation (Gingerich, 1977; Kay); finally, several

* Departamento de Prehistoria y Arqueología. Universidad de Granada, Spain.

** Instituto Universitario de la Paz y los Conflictos. Universidad de Granada, Spain.

***A Anthropological Institute \& Museum. Universtität Zürich, Switzerland. 
studies gave positive allometrically slopes what was used to support the seminal proposal of Pilbeam \& Gould about the significance of the relationship between teeth size and metabolic requirements (Pilbeam \& Gould; Smith et al., 1996; Vinyard \& Hanna).

However, the starting point for most analyses on the relationship between tooth size and metabolic requirements is the scaling relationship that both variables show separately with body mass. The only exception is the study of Vinyard \& Hanna for strepsirrhines, in which the relationship between basal metabolic rate and postcanine tooth size was evaluated directly. However, as indicated by McNab \& Eisenberg (1989), "A similarity in scaling, therefore, is alone an inadequate basis for concluding that a functional connection exists between (postcanine tooth size and metabolic requirements), even though such similarity has been widely used in this manner".

On the other hand, it has been widely assumed that the basal metabolic rate scaled geometrically in respect to body mass following the elastic similarity (3/4) (Glazier, 2005; Kleiber). However, the universality of such affirmation has been questioned (Kolokotrones et al., 2010; Lovegrove, 2000; White et al., 2009). Nevertheless, two previous studies on primates have pointed out that it is not possible to discard the 'traditional' metabolic exponent ( 0.75) for such taxonomic group even controlling for phylogenetic effects (Genoud, 2002; White et al.).

The inferences derived from exponents adjusted in the regression of tooth size on body mass are ambiguous and/or mixed, which results to a great extent from the diversity of variables used and/or taxonomic groups included in the analyses. For this reason, it seems necessary to evaluate the direct relationship of postcanine tooth size on metabolic requirements, because the mere 'equivalence between exponents' may not be reliable and the number of cases analyzed in previous studies uses to be low.

The objectives of this study are to evaluate: (1) which is the metabolic exponent derived from the relationship between body mass and metabolic requirements in a large dataset of living primates; and (2) which is the relationship between tooth size and metabolic requirements.

\section{MATERIAL AND METHOD}

Data compiled from the bibliography on postcanine tooth size, body mass and basal metabolic rate for 28 primate species were used (Table I). Occlusal surface area of postcanine teeth (PCOA, in $\mathrm{mm}^{2}$ ) was calculated from data published for strepsirrhines (Vinyard \& Hanna) and haplorrhines (Plavcan, 1990) by multiplying the mesiodistal length (MD) by the buccolingual breadth of the first two upper molars $\left(\mathrm{M}^{1}\right.$ and $\left.\mathrm{M}^{2}\right)$. Basal metabolic rates (BMR, in $\mathrm{ml} \mathrm{O}_{2} / \mathrm{h}$ ) were obtained from Isler et al. (2008) for those primate species with reliable measurements that could be compared. Body masses were taken from Smith \& Jungers (1997).

Null hypotheses $\left(\mathrm{H}_{0}\right)$ to be tested here are the following: (1) that the slope obtained in the regression adjusted for a given pair of variables is not statistically different from zero $\left[\mathrm{H}_{0}\left(\beta_{1}=0\right)\right]$; (2) that the slope does not differ significantly from isometry $\left[\mathrm{H}_{0}\left(\beta_{1}=\right.\right.$ isom) $]$; and (3) that the slope takes a value close to metabolic scaling, 3/4 $\left[\mathrm{H}_{0}\left(\beta_{1}=0.75\right)\right]$. The level of statistical confidence used was $\mathrm{p}<0.05$ in all cases. The value expected for the slope under conditions of isometry depends on the variable analyzed (Table II). When the regression involves two volumes, the isometric slope is 1 . If a surface is regressed on a volume, the expected slope is $2 / 3$. When the independent variable is linear and the dependent one a volume, the value is 3 . Finally, a surface should scale on a linear variable with exponent 2 . Given that the metabolic exponent is obtained from a regression between two volumes (basal metabolic rates, measured in $\mathrm{ml} / \mathrm{h}$, and body masses, proportional to animal volumes), the value expected for isometry is 1 . For this reason, in order to test if equivalence of exponents holds, the value for isometry must be multiplied by the metabolic exponent (3/4) (Table II).

Regression functions adjusted by ordinary lestsquares (OLS) and reduced major axis (RMA) were estimated using the statistical package PAST 1.0 (Hammer et al., 2001).

The ordinary least square (OLS) is the most used fitting technique, among other reasons because it is the technique included by default in the most of the statistic software packages. However, regressions adjusted by the means of OLS assume that the independent variable (Kleiber) is measured without error. When this assumption is violated, OLS underestimates the value of the correct slope, increasing the magnitude of such error when the correlation between variables decreases (Harvey \& Pagel, 1991). On the other hand, the use of OLS is appropriated when the relationship between variables is asymmetric. On the contrary, if we assume that such relationship is symmetric it is possible to use another fitting technique, the reduced major axis (RMA) (Smith, 2009). Though, in the vast majority of the cases of biological data, errors (measurements -technique and sampling-and equations -natural and measurement-) in both 
Table I. Variables used in the present study. BM: body mass; PCOA: superior postcanine tooth occlusal area; BRM: basal metabolic rate.

\begin{tabular}{|c|c|c|c|}
\hline Species & BM (kg) & $\operatorname{PCOA}\left(\mathbf{m m}^{2}\right)$ & $\mathrm{BRM}\left(\mathrm{ml} \mathrm{O}_{2} / \mathrm{h}\right)$ \\
\hline Alouatta palliata & 6.25 & 117.13 & 2000.3 \\
\hline Aotus trivirgatus & 0.99 & 24.18 & 455.5 \\
\hline Callithrix jacchus & 0.32 & 11.92 & 154 \\
\hline Callithrix pygmaea & 0.12 & 6.93 & 88.6 \\
\hline Leontopithecus rosalia & 0.61 & 22.00 & 381.5 \\
\hline Saimiri sciureus & 0.80 & 18.53 & 592 \\
\hline Saguinus oedipus & 0.43 & 13.95 & 449.5 \\
\hline Colobus guereza & 8.59 & 108.37 & 2978 \\
\hline Cercopithecus ascanius & 3.71 & 59.06 & 1798.6 \\
\hline Cercopithecus mitis & 6.11 & 78.15 & 3391.5 \\
\hline Erythrocebus patas & 9.45 & 102.82 & 1068 \\
\hline Homo sapiens & 60.50 & 246.49 & 12457 \\
\hline Hylobates lar & 5.60 & 79.24 & 1071 \\
\hline Macaca fascicularis & 4.25 & 88.49 & 3458 \\
\hline Macaca fuscata & 9.52 & 147.80 & 4191.7 \\
\hline Macaca mulatta & 6.92 & 111.73 & 2239 \\
\hline Papio anubis & 18.15 & 264.86 & 2940 \\
\hline Papio cynocephalus & 17.15 & 232.97 & 5784 \\
\hline Papio ursinus & 22.30 & 285.90 & 5147 \\
\hline Pan troglodytes & 44.97 & 250.11 & 9000 \\
\hline Pongo pygmaeus & 60.16 & 335.76 & 4941 \\
\hline Cheirogaleus medius & 0.28 & 10.2 & 195 \\
\hline Microcebus marinus & 0.06 & 6.17 & 42.3 \\
\hline Eulemur fulvus & 2.14 & 63.11 & 345 \\
\hline Lemur catta & 2.21 & 45.99 & 489 \\
\hline Varecia variegata & 3.58 & 85.77 & 603.6 \\
\hline Lepilemur mustelinus & 0.78 & 25.28 & 225.1 \\
\hline Propithecus verreauxi & 3.1 & 67.14 & 670 \\
\hline Arctocebus calabrensis & 0.31 & 28.35 & 131.2 \\
\hline Loris tardigradus & 0.27 & 17.72 & 128 \\
\hline Nycticebus coucang & 1.06 & 28.91 & 272.6 \\
\hline Perodicticus potto & 1.1 & 20.64 & 326.6 \\
\hline Euoticus elegantulus & 0.27 & 12.79 & 215.7 \\
\hline Galago moholi & 0.18 & 10.25 & 137.2 \\
\hline Galago senegalensis & 0.21 & 11.65 & 198 \\
\hline Galagoides demidoff & 0.06 & 8.04 & 63 \\
\hline Otolemur crassicaudatus & 1.15 & 31.74 & 523 \\
\hline Otolemur garnettii & 0.76 & 31.93 & 412.3 \\
\hline
\end{tabular}

variables (independent and dependent) are present and the relationship between variables is asymmetric (McArdle, 2003; Smith). It is therefore advisable to use both techniques, among other reasons because the values of different variables come from different samples.
Table II. Metabolic equivalences (based on 0.75 exponent) among different pair of variables; uni: unidimensional variable; bi: bidimensional variable; tri: tridimensional variable.

\begin{tabular}{lcc}
\hline Variables pair & Isometry & $\begin{array}{c}\text { Metabolic } \\
\text { exponent }\end{array}$ \\
\hline uni-uni & 1 & 0.75 \\
bi-bi & 1 & 0.75 \\
tri-tri & 1 & 0.75 \\
uni-bi & $1 / 2$ & 0.375 \\
uni-tri & $1 / 3$ & 0.2475 \\
bi-uni & 2 & 1.5 \\
bi-tri & 1.5 & 1.125 \\
tri-uni & 3 & 2.25 \\
tri-bi & $2 / 3$ & 0.5 \\
\hline
\end{tabular}

Finally, given that the species analysed are part of a hierarchically structured phylogeny, data collected from them do not necessarily satisfy the condition of statistical independence, thus hindering traditional (i.e., ahistorical) statistical analyses (Felsenstein, 1985; Harvey $\&$ Pagel). This translates in spuriously narrow confidence limits for the statistics used (i.e., increased type I error) and inaccurate estimations of the parameters of interest (Harvey \& Pagel). Both problems, however, can be largely circumvented by including phylogenetic information into the statistical analyses, in order to obtain phylogenetically independent data. For this reason, the original variables were transformed into their corresponding contrasts according to Phylogenetic Generalized LeastSquares (PGLS) by the means of the use of COMPARE 4.6b (Martins, 2004) as it is described by Martins and Hansen (Martins \& Hansen, 1997). COMPARE calculates the relationship between traits, while also taking phylogeny and within-taxon variation into account. A simple exponential model of constrained phenotypic evolution is applied, with an estimated alpha parameter (a) used to indicate the strength of the evolutionary constraint. When both within-species variation and the evolutionary constraint are close to zero, PGLS results will be identical to those produced using Felsenstein's independent contrasts method.

Composite trees, including branch length estimations, were constructed for reconstructing the phylogenetic relationships among the primate species studied (Isler et al.). 


\section{RESULTS}

Tables III and IV show the results obtained in the regression analyses. The slopes adjusted were statistically different from zero in all cases, with the only exception of the one obtained for the relationship between postcanine tooth size and basal metabolic rate when the effects of body size are discarded. All these regressions, except the last one, provided very high correlation coefficients $(r>0.90)$ and very low $\mathrm{p}$ values $(<0.0001)$. The null hypothesis for isometry $\left[\mathrm{H}_{0}\left(\beta_{1}=\mathrm{isom}\right)\right]$ was rejected for the relationships between basal metabolic rate and body mass (OLS, RMA and PGLS), because the slopes were allometrically negative in all cases. It was also rejected for the regressions of postcanine tooth size on body mass (OLS and PGLS), as the slopes were again significantly lower than the ones expected from isometry. On the contrary, the null hypothesis of isometry can be accepted for the relationship between basal metabolic rate and postcanine surface area (OLS, RMA and PGLS).

In addition, the null hypothesis of an exponent of 0.75 was rejected for the slopes between postcanine tooth size and body mass, with independence of the technique used in the adjustment.

Lastly, it is relevant to point out that, regarding the phylogenetic influence, there exist differences respecting each variable (Table IV). In the case of the regression between body size and basal metabolic rate and between this and the size of postcanine occlusal area, the phylogenetic influence is high because the $\partial$ values are close to zero. However, the phylogenetic influence is smaller for the relation between both, body and postcanine sizes, because the a value departs from zero.

Table III. Descriptive statistics of regression analyses for primate groups, OLS: ordinary least squares; RMA: reduced minor axis; BM: body mass (in kg); PCOA: postcanine teeth occlusal area (in $\mathrm{mm}^{2}$ ); BMR: basal metabolic rate (in $\mathrm{ml} \mathrm{O}_{2} / \mathrm{h}$ ); $\mathrm{N}$ : sample size; r: coefficient of signification; $\beta_{0}$ : Y-intercept; $\beta_{1}$ : slope; $H_{0}\left(\beta_{1}=0\right)$ : null hypothesis for slope zero; $H_{0}\left(\beta_{1}=\right.$ isom): null hypothesis for the slope values expected from geometric scaling (isometry); se: standard error; $H_{0}\left(\beta_{1}=0,75\right)$ : null hypothesis for the slope value expected from elastic similarity (allometry); ns: non-significant t-test value for comparison of slopes ( $p>0,05)$; (-): negative allometry; (+): positive allometry.

\begin{tabular}{|c|c|c|c|c|c|c|c|}
\hline OLS & $\mathbf{n}$ & $\mathbf{r}$ & $B_{0}( \pm \mathrm{se})$ & $B_{1}( \pm s e)$ & $\mathbf{H}_{0}\left(\boldsymbol{B}_{1}=\mathbf{0}\right)$ & $\mathrm{H}_{0}\left(B_{1=\mathrm{i}} \mathrm{SOm}\right)$ & $H_{0}\left(B_{1}=0.75\right)$ \\
\hline $\log B M R$ on $\log B M$ & 38 & 0.96 & $2.65( \pm 0.03)$ & $0.75( \pm 0.04)$ & $<0.0001$ & $<0.01(-)$ & $\mathrm{ns}$ \\
\hline $\log \mathrm{PCOA}$ on $\log \mathrm{BM}$ & 38 & 0.98 & $1.49( \pm 0.02)$ & $0.61( \pm 0.02)$ & $<0.0001$ & $<0.01(-)$ & $<0.0001$ \\
\hline $\log \mathrm{PCOA}$ on $\log \mathrm{BMR}$ & 38 & 0.93 & $-0.45( \pm 0.15)$ & $0.74( \pm 0.05)$ & $<0.0001$ & $\mathrm{~ns}$ & $\mathrm{~ns}$ \\
\hline RMA & $\mathrm{n}$ & $\mathrm{r}$ & $\beta_{0}( \pm \mathrm{se})$ & $\beta_{1}( \pm \mathrm{se})$ & $\mathrm{H}_{0}\left(\beta_{1}=0\right)$ & $\mathrm{H}_{0}\left(ß_{1}=\mathrm{i}\right.$ som $)$ & $\mathrm{H}_{0}\left(\beta_{1}=0.75\right)$ \\
\hline $\log \mathrm{BMR}$ on $\log \mathrm{BM}$ & 38 & 0.96 & $2.64( \pm 0.03)$ & $0.78( \pm 0.04)$ & $<0.0001$ & $<0.05(-)$ & $\mathrm{ns}$ \\
\hline $\log \mathrm{PCOA}$ on $\log \mathrm{BM}$ & 38 & 0.98 & $1.48( \pm 0.02)$ & $0.62( \pm 0.02)$ & $<0.0001$ & $<0.05(-)$ & $<0.0001$ \\
\hline $\log \mathrm{PCOA}$ on $\log \mathrm{BMR}$ & 38 & 0.93 & $-0.61( \pm 0.14)$ & $0.79( \pm 0.05)$ & $<0.0001$ & $<0.01(+)$ & $\mathrm{ns}$ \\
\hline Size adjusted (OLS) & $\mathrm{n}$ & $\mathrm{r}$ & $\beta_{0}( \pm \mathrm{se})$ & $\beta_{1}( \pm \mathrm{se})$ & $\mathrm{H}_{0}\left(\beta_{1}=0\right)$ & $\mathrm{H}_{0}\left(ß_{1}=\mathrm{isom}\right)$ & $\mathrm{H}_{0}\left(\beta_{1}=0.75\right)$ \\
\hline $\log \mathrm{PCOA}$ on $\log \mathrm{BMR}$ & 38 & - & - & - & $\mathrm{ns}$ & - & - \\
\hline
\end{tabular}

Table IV. Descriptive statistics of PGLS analyses for primate species, see legend to Table III, PGLS: phylogenetic generalized least squares; a: parameter used to indicate the strength of the evolutionary constraint.

\begin{tabular}{lccccccccc}
\hline PGLS & $\mathbf{n}$ & $\boldsymbol{\alpha}$ & $\mathbf{r}$ & $\mathbf{B}_{\mathbf{0}}( \pm \mathbf{s e})$ & $\boldsymbol{B}_{\mathbf{1}}( \pm \mathbf{s e})$ & $\mathbf{H}_{\mathbf{0}}\left(\boldsymbol{B}_{\mathbf{1}}=\mathbf{0}\right)$ & $\mathbf{H}_{\mathbf{0}}\left(\boldsymbol{B}_{\mathbf{1}}=\mathbf{i s o m}\right)$ & $\mathbf{H}_{\mathbf{0}}\left(\boldsymbol{B}_{\mathbf{1}}=\mathbf{0 . 7 5}\right)$ \\
\hline $\log \mathrm{BMR}$ on $\operatorname{logBM}$ & 36 & 15.50 & 0.93 & $2.64( \pm 0.04)$ & $0.73( \pm 0.05)$ & $<0.0001$ & $\mathrm{~ns}$ & $\mathrm{~ns}$ \\
$\log \mathrm{PCOA}$ on $\log \mathrm{BM}$ & 36 & 4.83 & 0.97 & $1.49( \pm 0.02)$ & $0.60( \pm 0.03)$ & $<0.0001$ & $<0.01(-)$ & $<0.0001$ \\
$\log$ PCOA on $\operatorname{logBMR}$ & 36 & 15.50 & 0.90 & $-0.39( \pm 0.16)$ & $0.72( \pm 0.06)$ & $<0.0001$ & $\mathrm{~ns}$ & $\mathrm{~ns}$ \\
\hline
\end{tabular}

\section{DISCUSSION}

For the same regressions, the fitting slopes calculated by OLS $\left[\mathrm{OLS}\left(\beta_{1}\right)\right]$ are shallower than the ones generated by RMA $\left[\operatorname{RMA}\left(\beta_{1}\right)\right]$ because the value of the second ones is obtained dividing the first ones by their respective coefficient of determination $\operatorname{OLS}(\mathrm{r})$ : $\operatorname{RMA}\left(\beta_{1}\right)=\operatorname{OLS}\left(\beta_{1}\right) / \mathrm{OLS}(\mathrm{r})$.
However, the values estimated for the slopes in this study tend to be similar with independence of the technique used in the adjustment (OLS or RMA). The reason is that the correlation coefficients obtained are remarkably high, close to one. However, the functional interpretation of the slope obtained for the relationship between tooth size and body mass depends on the regression method employed, because isometry ca not be discarded using RMA and can be rejected with OLS. 
In this specific case, the result does not seem to be related with this rule because the OLS(r) is very high $(0.97)$ and therefore its influence in the RMA $\left(\beta_{1}\right)$ calculation is minimal.

As it has been pointed out in the objectives of this study, it is important to discuss the relation between body mass and basal metabolic rate. In previous studies (Genoud; White et $a l$.) it has been stated that basal metabolic rate would scale following an allometrically negative slope in respect to body mass ( 0.75). This study coincides with such results, as the slopes are negative, without being able to discard the $3 / 4$ exponent, that points at (1) that there exists a significant bias in the sample used in the present study and (2) that such relation is independent of the phylogeny technique which uses PGLS instead of the Felstentein Independent Contrast (FIC) which were the techniques used in the two previous studies we referred to. Facing the FIC, PGLS is a much more flexible technique as it takes into account the strength of the evolutionary constrains.

Although different researchers have criticized the universal nature of Kleiber's law (Kolokotrones et al.; Lovegrove; White et al.), the results obtained in this study using PGLS instead of FIC allow to propose that primates follow such metabolic pattern.

For this reason, it is worth discussing here on: (1) the validity of the 'equivalence between exponents' argument, as initially proposed by Pilbeam \& Gould, which implies that the relationship of tooth size on metabolic requirements results from the similar relationships that both variables show with the body mass of animals; and (2) which is the contribution of our study to this debate.

Given the 'equivalence between exponents', the fact that occlusal surface area of the first two upper molars and body mass show negative allometry for primates implies that it is not possible to infer a functional link between tooth size and metabolic requirements. Such results coincide with those obtained in previous studies (Gingerich; Kay; Vinyard \& Hanna). However, the present study goes further; the result obtained here for the relationship between the estimates of basal metabolic rate and the dimensions of postcanine teeth is highly significant. Therefore, the existence or absence of a relationship between two variables depends on the $p$ value of the null hypothesis $\mathrm{H}_{0}\left(\beta_{1}=0\right)$, which is independent of the value obtained for the slope when any of these variables is regressed on a third one ( $\mathrm{McNab} \&$ Eisenberg).

A different matter is if the positive allometry found for tooth size on body mass reflects the metabolic function of postcanine teeth. Metabolic rate scales with negative allometry on body mass in primates. Therefore, in order to interpret that the variation in the size of a metric variable relates to body mass as a function of the metabolic requirements of animals, the allometric exponent obtained should be negative (i.e., 0.75 with respect to isometry). However, given that the area of postcanine teeth is a bidimensional variable that correlates with body mass, which is a tridimensional one, the exponent value equivalent to 0.75 would be 0.5 (i.e., $0.75 * 2 / 3$ ). Thus, the question is: why is there a persistent tendency to interpret the positive exponent of the regressions between tooth size and body mass as evidencing the metabolic function of postcanine teeth?

An explanation comes from the misinterpretation of Pilbeam \& Gould, who proposed that "Since we are plotting tooth area against a measure of length, slopes significantly greater than 2 will indicate positive allometry." However, they affirmed later "If tooth area increases as metabolism at the 0.75 power of body weight, we predict a slope of 2.25 $\left(0.75^{*} 3.0\right)$." This would be only valid if the area of postcanine teeth were a tridimensional variable (see Table II), but given that it is a bidimensional one, then the slope should be 1.5 (i.e., $0.75 * 2$ ). In any case, body size emerges as a determining factor for the relationship between tooth size and basal metabolic rate.

Therefore, if we resort to an approach based on 'equivalence between exponents', the value of the slopes obtained between a tridimensional variable, body mass, (independent variable) and another bidimensional one, the postcanine occlusal area (dependent variable) should approximate to $0.75 *(2 / 3)$, that is, 0.5 and therefore be allometrically negative.

The use of the 'equivalence between exponents' had and still has a clear practical sense, as there are variables that can not be measured in extinct organisms. One is their basal metabolic rate, which is a key for deriving ecophysiological inferences on ancient taxa. However, given the results shown here, it is necessary to introduce a cautionary note for those conclusions based on the 'equivalence between exponents', which can represent a major limitation for making inferences on the fossil record.

ACKNOWLEDGMENTS. Thanks are giving to Paul Palmqvist and Juan Antonio Pérez-Claros for comments have improved the early versions of this study. This research has been funded by the Spanish Ministry of Science and Innovation (projects CGL2011-30334 and HAR2008-04577) and supported by the Department of Economy, Innovation and Science, Junta de Andalucía, Spain (Research Group HUM-607). This study has been possible thanks to a Return Contract (University of Granada, Spain). 
JIMÉNEZ-ARENAS, J. M. Tamaño de la dentición y requerimientos metabólicos en Primates: La ‘equivalencia entre exponentes’ bajo discusión. Int. J. Morphol., 31(4):1191-1197, 2013.

RESUMEN: El significado funcional del tamaño de los dientes, y más concretamente del tamaño de la dentición poscanina, ha contribuido al desarrollo de una vasta literatura científica. No obstante, casi todos estos trabajos se han centrado en la 'equivalencia entre exponentes'. Así, cuando el tamaño de los dientes escala siguiendo una pendiente de 0,75 respecto al tamaño corporal se interpreta que las diferencias en tamaño reflejan los cambios en los requerimientos metabólicos. Si, por el contrario, el exponente obtenido es cercano a la isometría, la inferencia que se establece es que el cambio en el tamaño de la dentición es una consecuencia incidental del cambio en el tamaño corporal. En este artículo mostramos los resultados de un estudio en el que se han evaluado las relaciones entre el área de la dentición poscanina (PCOA) y la tasa metabólica basal (BMR) en 28 especies de primates. Los resultados obtenidos indican, en primer lugar, que existe una fuerte correlación entre BMR y PCOA, incluso cuando el efecto de la filogenia es controlado. Sin embargo, cuando se evita el efecto del tamaño no se puede descartar que la pendiente sea igual a cero. En segundo lugar, cuando se realiza una regresión usando el tamaño corporal (BM) como variable independiente y PCOA como dependiente, la pendiente obtenida es alométricamente negativa, lo que se mantiene cuando se controla para la filogenia. Dado que los resultados son contradictorios, sugerimos que la regla de la 'equivalencia entre exponentes' no es una buena aproximación para obtener inferencias sobre la función de la dentición poscanina. El argumento para la existencia o no de una relación entre dos variables debe de estar basada en el valor de $p$ usado para testar la hipótesis nula $\mathrm{H}_{0}\left(\beta_{1}=0\right)$ la cual es independiente del valor tomado por cada una de esas variables (PCOA y BMR) cuando es regresada sobre una tercera (BM). En cualquier caso, el tamaño corporal emerge como un factor clave en la relación entre el tamaño de la dentición poscanina y la tasa metabólica basal en primates

PALABRAS CLAVE: Tamaño de la dentición poscanina; Tasa metabólica basal; Alometría; Tamaño corporal.

\section{REFERENCES}

Copes, L. E. \& Schwartz, G. T. The scale of it all: Postcanine tooth size, the taxon-level effect, and the universality of Gould's scaling law. Paleobiology, 36(2):188-203, 2010.

Felsenstein, J. Phylogenies and the comparative method. Am. Nat., 125(1):1-15, 1985.

Genoud, M. Comparative studies of basal rate of metabolism in primates. Evol. Anthropol., 11(S1):108-11, 2002.

Gingerich, P. D. Correlation of tooth size and body size in living hominoid primates, with a note on relative brain size in Aegyptopithecus and Proconsul. Am. J. Phys. Anthropol., 47(3):395-8, 1977.

Glazier, D. S. Beyond the '3/4-power law': variation in the intraand interspecific scaling of metabolic rate in animals. Biol. Rev. Camb. Philos. Soc., 80(4):611-62, 2005.

Hammer, O.; Harper, D. A. T. \& Ryan, P. D. PAST: Paleontological statistics software package for education and data analysis. Paleontol. Electron., 4(1):9, 2001.

Harvey, P. H. \& Pagel, M. D. The Comparative Method in Evolutionary Biology. New York, Oxford University Press, 1991.

Isler, K.; Kirk, C. E.; Miller, J. M.; Albrecht, G. A.; Gelvin, B. R. \& Martin, R. D. Endocranial volumes of primate species: scaling analyses using a comprehensive and reliable data set. J. Hum. Evol., 55(6):967-78, 2008.
Kay, R. F. The functional adaptations of primate molar teeth. Am. J. Phys. Anthropol., 43(2):195-216, 1975.

Kleiber, M. The Fire of Life: An Introduction to Animal Energetics. New York, Wiley, 1961.

Kolokotrones, T.; Van, S.; Deeds, E. J. \& Fontana, W. Curvature in metabolic scaling. Nature, 464(7289):753-6, 2010.

Lovegrove, B. G. The zoogeography of Mammalian basal metabolic rate. Am. Nat., 156(2): 201-19, 2000.

Martins, E. P. COMPARE, version 4.6b. Computer programs for the statistical analysis of comparative data. Bloomington, Department of Biology, Indiana University, 2004.

Martins, E. P. \& Hansen, T. F. Phylogenies and the comparative method: A general approach to incorporating phylogenetic information into the analysis of interspecific data. Am. Nat., 149(4):646-67, 1997.

McArdle, B. H. Lines, models, and errors: Regression in the field. Limnol. Oceanogr., 48(3):1363-6, 2003.

McNab, B. K. \& Eisenberg, J. F. Brain size and its relation to the rate of metabolism in mammals. Am. Nat., 133(2):157-67, 1989.

Pilbeam, D. \& Gould, S. J. Size and scaling in human evolution. Science, 186(4167):892-901, 1974.

Plavcan, J. M. Sexual Dimorphism in the Dentition of Extant 
JIMÉNEZ-ARENAS, J. M. Tooth size and metabolic requirements in Primates: The 'equivalence between exponents' under discussion. Int. J. Morphol., 31(4):1191-1197, 2013.

Anthropoid Primates. Durham, Department of Biological Anthropology and Anatomy Duke University, 1990.

Smith, R. J. Use and misuse of the reduced major axis for linefitting. Am. J. Phys. Anthropol., 140(3):476-86, 2009.

Smith, R. J.; Albrecht, G. H.; Damuth, J.; Bacco, M. D.; Fortelius, M.; Gingerich, P. D.; Godfrey, L. R.; Sutherland, M. R.; Jungers, W. L.; Leigh, S. R.; Leney, M. D.; Foley, R. A.; Leonard, W. R.; Robertson, M. L.; Leutenegger, W.; McHenry, H. M.; Martin; R. D.; Pilbeam, D.; Plavcan, J. M.; Wheeler, P. E.; Wood, B. A. \& Collard, M. Biology and body size in human evolution: Statistical inference misapplied [and Comments and Reply]. Curr. Anthropol., 37(3):451-81, 1996.

Smith, R. J. \& Jungers, W. L. Body mass in comparative primatology. J. Hum. Evol., 32(6):523-59, 1997.

Vinyard, C. J. \& Hanna, J. Molar scaling in strepsirrhine primates. J. Hum. Evol., 49(2):241-69, 2005.

White, C. R.; Blackburn, T. M. \& Seymour, R. S. Phylogenetically informed analysis of the allometry of Mammalian basal metabolic rate supports neither geometric nor quarter-power scaling. Evolution, 63(10):2658-67, 2009.

\author{
Correspondence to: \\ Juan Manuel Jiménez-Arenas \\ Departamento de Prehistoria y Arqueología \\ Campus Universitario de Cartuja s/n. \\ Universidad de Granada \\ 18071 Granada \\ ESPAÑA \\ Phone: +34 958246355 \\ Fax: $\quad+34958244981$ \\ Email: jumajia@ugr.es
}

Received: 08-05-2013

Accepted: 10-08-2013 